\title{
Numerical Simulation of Innovative Air Capture Systems Based On Bladeless Technology
}

\author{
Maurizio Carlini', Andrea Mennuni', Mirko Rotondo², Stefano Morelli² \\ ${ }^{1}$ CIRDER, University of Tuscia, 01100 Viterbo, Italy \\ maurizio.carlini@unitus.it; andrea.mennuni@unitus.it \\ ${ }^{2}$ DEIm, University of Tuscia, 01100 Viterbo, Italy \\ mirko.rotondo@unitus.it; stefano.morelli894@gmail.com
}

\begin{abstract}
This work focuses on the feasibility study of a new suction hood model that allows the complete disposal of the fumes produced during cooking. The originality of this study lies in the conception of a new functional geometry meant to reduce consumption, focusing on the increase of both efficiency and aspiration efficiency. The new technology is based on the Coandă effect applied on two innovative air capture systems of hood model. On one hand the air flow amplifier, a system that, starting from a low inlet flow rate, allows 10 times increasing of the output flow rate. On the other hand, the bladeless fan, which is usually implemented in newest bladeless ventilation systems. A simulation campaign has been conducted with COMSOL Multiphysics software to validate the simulation scenarios comparing the experimental results with respective references. For the post-validation step, the parametric sweep function has been used to study the system behaviours to every change of velocity, flow rate and extension of the ejector. The obtained results show the feasibility of these new suction systems, which present lower consumptions than other modern ventilation systems for kitchens. The computed results show that the perimeter velocity is in accordance with European standards. The perimeter velocity for air flow amplifier geometry allows a suction capacity range between $460 \mathrm{~m}^{3} / \mathrm{h}$ and $3600 \mathrm{~m}^{3} / \mathrm{h}$. In the bladeless fan case, the suction capacity is in a range between $325 \mathrm{~m}^{3} / \mathrm{h}$ and $2500 \mathrm{~m}^{3} / \mathrm{h}$. Therefore, the two geometries can be installed for both domestic and commercial kitchens.
\end{abstract}

Keywords: Bladeless technology; Coandă effect; air capture system; extractor hood; COMSOL Multiphysics; CFD analysis; multiparametric analysis.

\section{Introduction}

In order to reduce pollution emissions, innovative technologies are growing in accordance with current EU standards in terms of energy efficiency, in coupling with the renewable sources.

Hoods for fumes extraction are present in all homes, inside industries and in catering environments. Their main function, especially in the kitchen environment, is to extract the cooking fumes, improving the air quality where the device is installed [1]. Clearly, the position is a crucial consideration, since an incorrect placement leads to fumes and pollutants stagnation inside the dwelling [2]. For a correct ejection of the produced fumes, a fan must be installed to allow and guarantee a sufficient prevalence and flow rate, managing to overcome the load losses generated by the presence of the filter (to remove solid particles and liquids of grease and steam contained by the fluid crossing the hood) [3]-[5].

The design of the aspiring systems must be provided in accordance with different European standards and requirements. Moreover, the size and type (professional or domestic) of the installation environment have to be considered. The fundamental parameter is the calculation of the right suction flow for the disposal from the surrounding environment, of the main cooking fumes pollutants, in order to avoid the spread of contaminants inside the housing structure [6]-[9]. Proper design finds the right compromise between the aspirated flow rate that allows the disposal of all pollutants and the higher energy efficiency [10], [11], always in accordance with EU directives [12]. In fact, the world is moving to sustainable principles by means of known technologies optimization, such as for the building sector [13], [14], for the photovoltaic system [15], [16], for the biological conversion [17]-[19] using different input biomasses [20]-[22] and for the geothermal field [23], [24]. The study of these technologies can be extended by a simulation software, allowing the development of numerical campaigns on virtual prototypes [25], [26], reducing the production costs in the meanwhile [27], [28].

This work aims to define the velocity field of $\mathrm{n} .2$ hood models with bladeless technology through COMSOL Multiphysics software, validating the simulation scenarios with the reference data. Then, a parametrization is used to change 
the geometry (ejectors), velocity and flow rate, observing the feasibility and the behavior of the systems. The various advantages of the installation of the bladeless technology are the absence of moving parts in the suction area (vibrations are not produced), reduced cleaning and maintenance, low noise, high suction capacity, reduced weight and consumption.

\section{Materials and methods}

\subsection{Experimental Characterization}

The study involves the collection of bibliographical data that will be used as a reference for numerical simulations. Two different geometries are analyzed, a first geometry called Air flow amplifier, basically an air amplifier, and a second one called Bladeless fan. Both of these models take advantage of the Coandă effect which leads to an increase in terms of output flow, which is even 10 times higher than the inbound one. In particular, for the Air flow amplifier, several elaborations concerning optimization and CFD simulation (Computational Fluid Dynamics) have been reported by [29], [30], while for the Bladeless fan the main reference has been provided by the engineering company BW Engineering (C) and the company Dassault Systèmes ${ }^{\circledR}$, developer of the Abaqus software and CAD software SolidWorks ${ }^{\circledR}$. For both models, given the high complexity, CAD-based software has been used to extrapolate the correct measurements. Therefore, several papers have been analyzed for the Bladeless fan [29], [30]: for both geometry [31]-[33] and simulation conditions the geometry a tutorial by the engineering company BW Engineering has been chosen [34].

\subsection{Main Physical Phenomena Identification and Implementation}

The Coandă effect indicates that a flow flowing over a surface is influenced by two simultaneous forces. The global effect is a deviation of the fluid layers near the surface, as such layers show a tendency to adhere to the same surface [35]. Multiple applications have been developed about Coandă effect, leading to significant improvements both in aeronautics [29] and in medicine [36], [37].

The analysis is carried out through COMSOL Multiphysics (CM), a multiphysical simulations software which provided a multidisciplinary approach to the physics and phenomena to implement within the scenario. CM resolution approach is based on the Finite Element Method (FEM) to solve physical models and engineering problems [38]-[40]. Several papers have been consulted to understand the phenomenon before its implementation in CM [41]-[43]. In this particular case, axisymmetric 2D geometry is chosen as a spatial dimension and the CFD module is used for physics. By means of the CFD module, as provided by $\mathrm{CM}$, it is possible to model in the same scenario environment both the heat transfer to solids or fluids and reagent flows. In this study, the "Turbulent Flow" interface of the "Single-Phase Flow" model contained within COMSOL Multiphysics's "Fluid Flow" module is selected [44].

\subsection{Simulation Campaign}

The strategy of the simulation campaign is based on the reference data obtained by bibliography. The full geometry is defined in CM as shown by Fig. 1a and Fig. 1b for the Airflow amplifier and Bladeless fan, respectively.

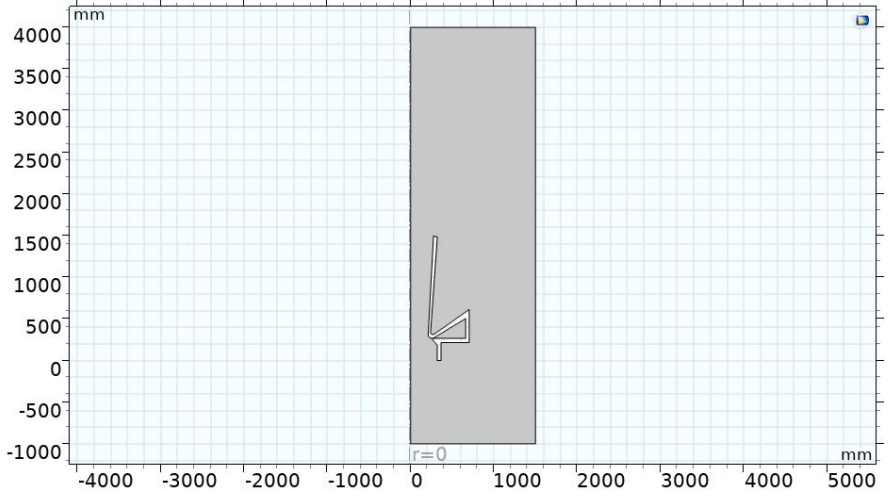

(a)

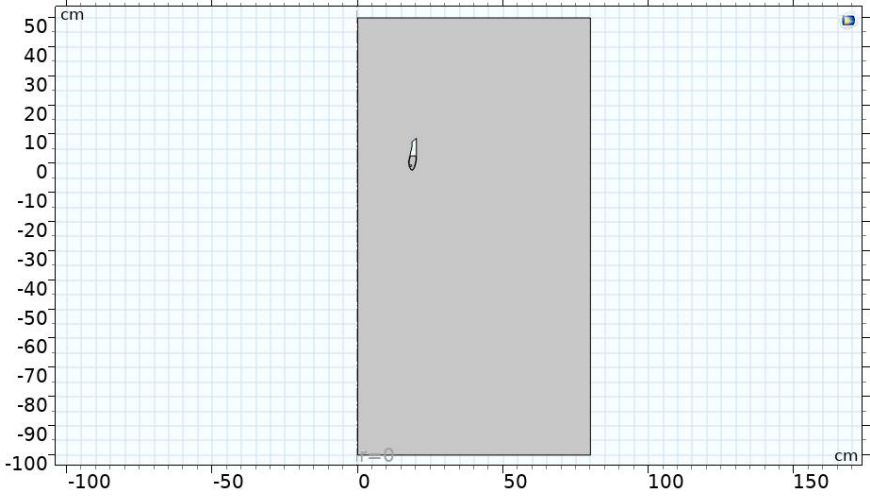

(b)

Fig. 1: The whole geometry of: a) Air flow amplifier; b) Bladeless fan. 
Once the geometry is designed, it is possible to pass through the materials selection and assignment. In this case the material that needs to be selected is air. The boundary conditions made for the study of turbulent flow $k-\varepsilon$ are the following: wall (No slip), inlet where the mass flow $\left(m_{\text {in }}=0,25 \mathrm{~kg} / \mathrm{s}\right)$ is inserted for the Air flow amplifier model while the condition of velocity $\left(v_{\text {in }}=2 \mathrm{~m} / \mathrm{s}\right)$ is implemented for the Bladeless fan model, outlet by using the pressure condition for both geometries and open contour to identify the boundary where incoming and outcoming fluxes are possible. Then, the model is meshed and calculated by means of a stationary approach. The simulation output is the $2 \mathrm{D}$ velocity across the whole geometry. Once the scenarios have been validated, a parametric sweep is conducted to carry out a wider analysis. In this case, for both geometries a sweep is initialized referring to n. 2 parameters and, for each of them, 4 different values are considered. It follows that $\mathrm{n} .16$ scenarios are solved. Referring to the Air flow amplifier scenario, the flow rate $\left(m_{\text {in }}\right)$ and the curvature of the arcs (that influences the ejector opening) change, as defined by Table 1. In the case of the Bladeless fan scenario, the velocity $\left(v_{i n}\right)$ and the point that defines the ejector opening vary, as defined by Table 1 . The different combinations allow the study of the velocity field of the two systems as the inlet conditions and the ejector opening change. Then, it is possible to identify which configuration should be used for a specific application.

Table 1: Parametric sweep for the Air flow amplifier.

\begin{tabular}{l|l|llll}
\hline & Parameter & \multicolumn{4}{|c}{ Value } \\
\hline \multirow{2}{*}{ Air flow amplifier } & ejector $[\mathrm{mm}]$ & 0,30 & 0,50 & 0,55 & 0,65 \\
\cline { 2 - 6 } & $m_{\text {in }}[\mathrm{kg} / \mathrm{s}]$ & 0,10 & 0,15 & 0,20 & 0,25 \\
\hline \multirow{2}{*}{ Bladeless fan } & ejector $[\mathrm{mm}]$ & 1,00 & 1,15 & 1,30 & 1,40 \\
\cline { 2 - 6 } & $v_{\text {in }}[\mathrm{m} / \mathrm{s}]$ & 1,00 & 2,00 & 3,00 & 4,00 \\
\hline
\end{tabular}

\section{Results}

\subsection{Numerical scenarios validation}

The first step is the validation of the scenarios comparing the results obtained by numerical simulation (from COMSOL Multiphysics) with the ones by reference data. The maximum discrepancy of these results has been fixed up to $5.0 \%$, which follows the scenario validation. The velocity field in the whole geometry is reported by Fig. 2 and Fig. 3 for the Air flow amplifier and Bladeless fan scenarios, respectively. Calculating the discrepancies in different points, the obtained values satisfy the discrepancy requirement for both models, therefore the numerical scenarios can be considered validated.

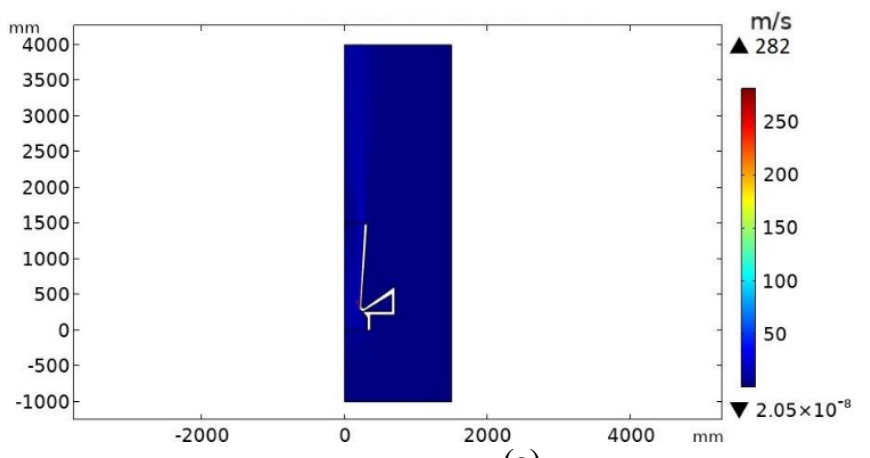

(a)

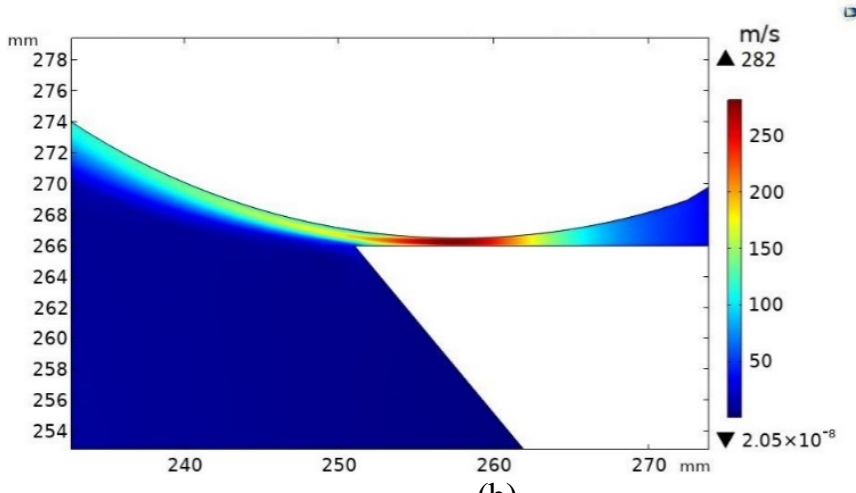

(b)

Fig. 2: Velocity field of the Air flow amplifier scenario: a) whole implemented geometry; b) focus around the ejector. 


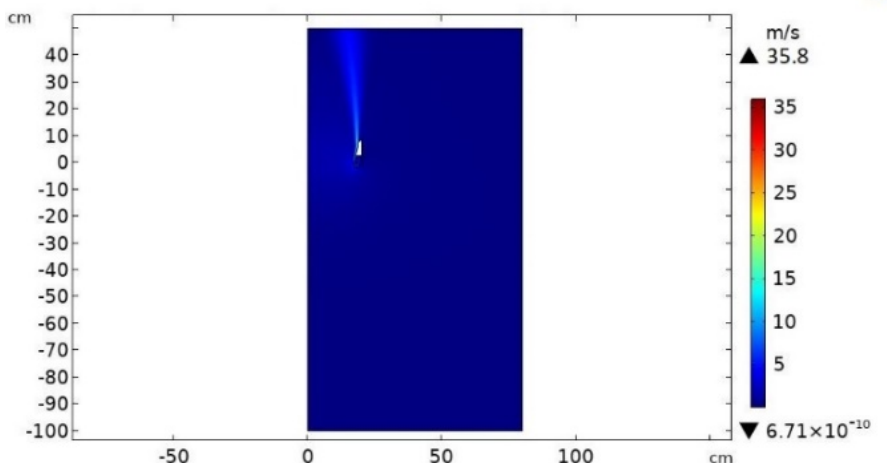

(a)

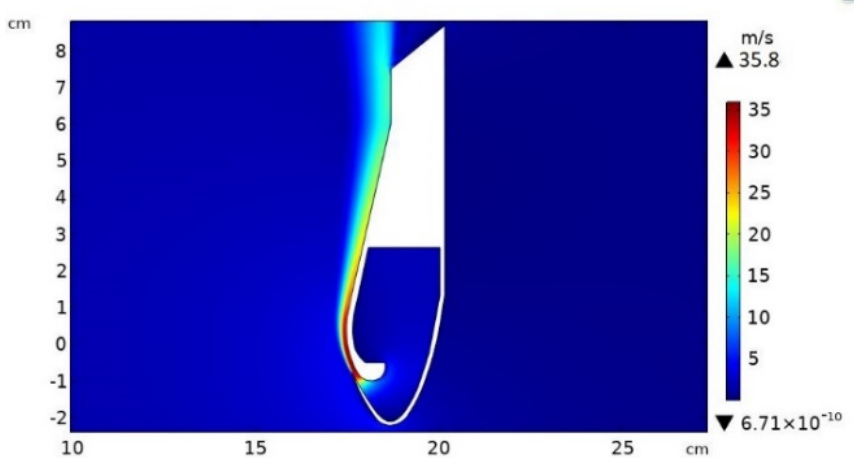

(b)

Fig. 3: Velocity field of the Bladeless fan scenario: a) whole implemented geometry; b) focus on the "shovel".

More in details, once validating numerical scenarios, Table 2 defines the simulation results compared with the reference data to calculate the discrepancy for the Air flow amplifier and Bladeless fan models.

Table 2. Validation of the models with the reference values for both Air flow amplifier [29] and Bladeless fan [34] scenarios.

\begin{tabular}{l|l|c|c|c}
\hline \multirow{2}{*}{ Model } & Value & $\begin{array}{c}\text { Reference data } \\
{[\mathbf{m} / \mathbf{s}]}\end{array}$ & $\begin{array}{c}\text { Simulation result } \\
{[\mathbf{m} / \mathbf{s}]}\end{array}$ & $\begin{array}{c}\text { Discrepancy } \\
{[\%]}\end{array}$ \\
\hline \multirow{4}{*}{ Air flow amplifier } & maximum velocity & 281,50 & 282,00 & 0,18 \\
\cline { 2 - 5 } & ejector output velocity & $200,00-210,00$ & 203,00 & $1,50-3,33$ \\
\cline { 2 - 5 } & velocity on curvature & 180,00 & 174,00 & 3,33 \\
\hline \multirow{2}{*}{ Bladeless fan } & maximum velocity & 35,09 & 35,80 & 2,02 \\
\cline { 2 - 5 } & queue velocity & $15,00-16,00$ & 15,58 & $3,87-2,63$ \\
\hline
\end{tabular}

\subsection{Parametric analysis}

Explicit selections are defined through the "Definitions" section of CM. These selections are used to calculate the velocity at increasing distances from the perimeter edge for the Air flow amplifier and Bladeless fan model, respectively. In order to understand if a hood could be installed inside a commercial or domestic room, it is very important to consider the velocity on the perimeter edge. Its value is required to be higher than $0,25 \mathrm{~m} / \mathrm{s}$ (referring to European standards). In Table 3 , the velocity results are reported depending on the opening of the ejector and the distance from the edge of the hood in different values of inlet flow rate for the Air flow amplifier. In Table 4, the velocity results are reported depending on the opening of the ejector and the distance from the edge of the hood in different values of inlet velocity for the Bladeless fan. Results highlighted in red identify the perimeter velocities that need to be compared with the minimum ones eligible by the European standards.

Table 3: Perimeter velocity values at different heights for different ejector openings and inlet flow rates (Air flow amplifier).

\begin{tabular}{l|c|c|c|c|c|c|} 
& \multirow{2}{*}{$\mathbf{A E} /$ Point } & \multicolumn{5}{|c}{ Velocity at different heights $[\mathbf{m} / \mathbf{s}]$} \\
\cline { 2 - 7 } & & $\mathbf{0} \mathbf{c m}$ & $\mathbf{2 5} \mathbf{~ c m}$ & $\mathbf{4 5} \mathbf{~ c m}$ & $\mathbf{6 5} \mathbf{~ c m}$ & $\mathbf{8 5} \mathbf{~ c m}$ \\
\hline \multirow{3}{*}{$\boldsymbol{m}_{\boldsymbol{i n}}=\mathbf{0 , 1 0} \mathbf{~ k g} / \mathbf{s}$} & $0,30[\mathrm{~mm}]$ & 0,68 & 0,66 & 0,36 & 0,18 & 0,09 \\
\cline { 2 - 7 } & $0,50[\mathrm{~mm}]$ & 0,53 & 0,50 & 0,31 & 0,16 & 0,08 \\
\cline { 2 - 7 } & $0,55[\mathrm{~mm}]$ & 0,48 & 0,45 & 0,30 & 0,15 & 0,07 \\
\hline \hline \multirow{2}{*}{$\boldsymbol{m}_{\text {in }}=\mathbf{0 , 1 5} \mathbf{~ k g} / \mathbf{s}$} & $0,65[\mathrm{~mm}]$ & 0,40 & 0,38 & 0,28 & 0,14 & 0,07 \\
\cline { 2 - 7 } & $0,30[\mathrm{~mm}]$ & 1,45 & 1,19 & 0,55 & 0,28 & 0,14 \\
\hline
\end{tabular}




\begin{tabular}{c|c|c|c|c|c|c}
\hline & $0,55[\mathrm{~mm}]$ & 1,05 & 0,98 & 0,46 & 0,23 & 0,11 \\
\cline { 2 - 7 } & $0,65[\mathrm{~mm}]$ & 0,89 & 0,91 & 0,42 & 0,21 & 0,10 \\
\hline \hline \multirow{3}{*}{$\boldsymbol{m}_{\boldsymbol{i n}}=\mathbf{0 , 2 0 ~ k g / s}$} & $0,30[\mathrm{~mm}]$ & 2,31 & 1,61 & 0,75 & 0,38 & 0,19 \\
\cline { 2 - 7 } & $0,50[\mathrm{~mm}]$ & 1,92 & 1,38 & 0,64 & 0,32 & 0,16 \\
\cline { 2 - 7 } & $0,55[\mathrm{~mm}]$ & 1,76 & 1,33 & 0,62 & 0,31 & 0,15 \\
\cline { 2 - 7 } & $0,65[\mathrm{~mm}]$ & 1,51 & 1,23 & 0,57 & 0,29 & 0,14 \\
\hline \hline \multirow{3}{*}{$\boldsymbol{m}_{\boldsymbol{i n}}=\mathbf{0 , 2 5} \mathbf{~ k g} / \mathbf{s}$} & $0,30[\mathrm{~mm}]$ & 3,08 & 2,02 & 0,94 & 0,47 & 0,24 \\
\cline { 2 - 7 } & $0,50[\mathrm{~mm}]$ & 2,64 & 1,74 & 0,81 & 0,41 & 0,20 \\
\cline { 2 - 7 } & $0,55[\mathrm{~mm}]$ & 2,44 & 1,67 & 0,78 & 0,39 & 0,19 \\
\cline { 2 - 7 } & $0,65[\mathrm{~mm}]$ & 2,14 & 1,55 & 0,72 & 0,36 & 0,18
\end{tabular}

Table 4: Perimeter velocity values at different heights for different ejector openings and inlet velocities (Bladeless fan).

\begin{tabular}{|c|c|c|c|c|c|c|}
\hline \multirow[t]{2}{*}{ 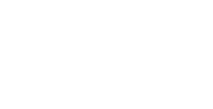 } & \multirow{2}{*}{ AE / Point } & \multicolumn{5}{|c|}{ Velocity at different heights $[\mathrm{m} / \mathrm{s}]$} \\
\hline & & $\mathbf{0} \mathbf{~ c m}$ & $25 \mathrm{~cm}$ & $45 \mathrm{~cm}$ & $65 \mathrm{~cm}$ & $85 \mathrm{~cm}$ \\
\hline \multirow{4}{*}{$v_{i n}=1,0 \mathrm{~m} / \mathrm{s}$} & $1,00[\mathrm{~mm}]$ & 1,25 & 0,15 & 0,06 & 0,03 & 0,01 \\
\hline & $1,15[\mathrm{~mm}]$ & 1,20 & 0,14 & 0,06 & 0,03 & 0,01 \\
\hline & $1,30[\mathrm{~mm}]$ & 1,13 & 0,13 & 0,05 & 0,03 & 0,01 \\
\hline & $1,40[\mathrm{~mm}]$ & 1,06 & 0,12 & 0,05 & 0,02 & 0,01 \\
\hline \multirow{4}{*}{$v_{i n}=2,0 \mathrm{~m} / \mathrm{s}$} & $1,00[\mathrm{~mm}]$ & 3,10 & 0,30 & 0,12 & $\overline{0,06}$ & 0,02 \\
\hline & $1,15[\mathrm{~mm}]$ & 2,97 & 0,29 & 0,12 & 0,05 & 0,02 \\
\hline & $1,30[\mathrm{~mm}]$ & 2,72 & 0,26 & 0,11 & 0,05 & 0,02 \\
\hline & $1,40[\mathrm{~mm}]$ & 2,52 & 0,25 & 0,10 & 0,05 & 0,02 \\
\hline \multirow{4}{*}{$v_{i n}=3,0 \mathrm{~m} / \mathrm{s}$} & $1,00[\mathrm{~mm}]$ & 5,18 & 0,46 & 0,19 & 0,09 & 0,03 \\
\hline & $1,15[\mathrm{~mm}]$ & 5,00 & 0,44 & 0,18 & 0,08 & 0,03 \\
\hline & $1,30[\mathrm{~mm}]$ & 4,63 & 0,40 & 0,17 & 0,08 & 0,03 \\
\hline & $1,40[\mathrm{~mm}]$ & 4,30 & 0,38 & 0,16 & 0,07 & 0,03 \\
\hline \multirow{4}{*}{$v_{i n}=4,0 \mathrm{~m} / \mathrm{s}$} & $1,00[\mathrm{~mm}]$ & 7,26 & 0,61 & 0,25 & $\overline{0,11}$ & 0,04 \\
\hline & $1,15[\mathrm{~mm}]$ & 6,96 & 0,58 & 0,24 & 0,11 & 0,04 \\
\hline & $1,30[\mathrm{~mm}]$ & 6,47 & 0,54 & 0,22 & 0,10 & 0,04 \\
\hline & $1,40[\mathrm{~mm}]$ & 6,07 & 0,51 & 0,21 & 0,10 & 0,04 \\
\hline
\end{tabular}

\section{Discussion}

The study highlighted the feasibility of the creation of suction hoods with Air flow amplifier and Bladeless fan geometry, identifying which of the two solutions should be the most suitable to be implemented into domestic or commercial environments. European standards were consulted for the benchmarks, in particular for the velocity on the perimeter edge of the hood, the minimum required value to be considered was $0,25 \mathrm{~m} / \mathrm{s}$. The identification of the punctual velocities at different distances from the perimeter edge of the hood was conducted for n. 5 points. Table 3 shows slightly lower values for distances from the edge of the hood of 65,00 and $85,00 \mathrm{~cm}$, but a correct suction of the fumes remains possible. In fact, the standard prescribes that the velocity on the perimeter edge of the hood must be equal to or greater than $0,25 \mathrm{~m} / \mathrm{s}$ and, in the case of Air flow amplifier geometry, this condition is always respected for all analyzed incoming flows. The choice to evaluate the development of velocity at different distances from the hood boundary allows to identify which configuration can be installed as required. In particular, once computed results have been evaluated, it should be possible to identify which solution, with the same ejector opening, is the most affordable for the consumption while maintaining a correct expulsion of the smokes produced. The flow rates generated by the system is between $460,00 \mathrm{~m}^{3} / \mathrm{h}$ and $3600,00 \mathrm{~m}^{3} / \mathrm{h}$, so this system could be used 
for both kitchens in domestic and commercial contexts. For the collection of Bladeless fan system data, the same steps and types of evaluation are performed. Table 4 shows a decreasing trend of velocity as the distance from the edge increases, reaching very low values at distances of $65,00 \mathrm{~cm}$ and $85,00 \mathrm{~cm}$ but the velocity on the perimeter edge is still greater than the minimum required. In general, with Bladeless fan geometry the reached flow rates are lower than the Air flow amplifier, being between $325,00 \mathrm{~m}^{3} / \mathrm{h}$ and $2500,00 \mathrm{~m}^{3} / \mathrm{h}$. Furthermore, the obtained data for both geometries identify a progressive velocity decrease while ejector opening increasing.

\section{Conclusion}

The study highlights the possibility to install both systems in home and commercial kitchen environments using bladeless technology. Two models have been investigated: the Air flow amplifier and the Bladeless fan. The Air flow amplifier and the Bladeless fan have been validated comparing the 2D stationary Finite Element Method simulation scenarios with the reference data in terms of reached velocities. The used method for the validation is the calculation of the discrepancy between numerical and bibliography data: the values are below the imposed upper limit of 5\%. Then, a parametrization of input values is conducted to study the behavior of the systems and to understand if these models can be work correctly in different input conditions. The chosen parameters for the Air flow amplifier are the ejector opening and the inlet flow rate while for the Bladeless fan those parameters are the ejector opening and the inlet velocity. For different opening conditions of ejector, referring to both models, the velocity on the perimeter edge of the hood is compared with the European standard, which is imposed at $0,25 \mathrm{~m} / \mathrm{s}$. All the collected velocities on the perimeter point overcome the European limit, therefore the studied geometries could be used. These models have to be slipped into the real case to understand the needs of real field application. Furthermore, the Air flow amplifier (powered by a compressor) could work correctly even inside larger kitchens, since the maximum flow rates are greater than Bladeless fan geometry (system powered by an engine with a fan, also positioned at a distance of $60,00 \mathrm{~cm}$ ).

\section{References}

[1] O. Han, A. Li, and R. Kosonen, "Hood performance and capture efficiency of kitchens: A review," Build. Environ., vol. 161, no. May, 2019,

[2] Y. Li and A. Delsante, "Derivation of capture efficiency of kitchen range hoods in a confined space," Build. Environ., vol. 31, no. 5, pp. 461-468, 1996,

[3] D. Rim, L. Wallace, S. Nabinger, and A. Persily, "Reduction of exposure to ultrafine particles by kitchen exhaust hoods: The effects of exhaust flow rates, particle size, and burner position," Sci. Total Environ., vol. 432, pp. 350-356, 2012,

[4] K. Lim and C. Lee, "A numerical study on the characteristics of flow field, temperature and concentration distribution according to changing the shape of separation plate of kitchen hood system," Energy Build., vol. 40, no. 2, pp. 175-184, 2008 ,

[5] W. Chen, J. Li, C. Wang, X. Dai, and J. Liu, "2D-PIV measurement of range hood-driven flow in a domestic kitchen," Energy Build., vol. 177, pp. 64-76, 2018,

[6] L. Lv, J. Gao, L. Zeng, C. Cao, J. Zhang, and L. He, "Performance assessment of air curtain range hood using contaminant removal efficiency: An experimental and numerical study," Build. Environ., vol. 188, no. November 2020, p. 107456, 2020,

[7] J. D. Clark, G. Rojas, and I. S. Walker, "Towards the development of a standardized testing protocol for overhead island kitchen exhaust devices: Procedures, measurements and paths forward," Build. Environ., vol. 142, no. March, pp. 301311,2018 ,

[8] G. Buonanno, L. Morawska, and L. Stabile, "Particle emission factors during cooking activities," Atmos. Environ., vol. 43, no. 20, pp. 3235-3242, 2009,

[9] K. L. Abdullahi, J. M. Delgado-Saborit, and R. M. Harrison, "Emissions and indoor concentrations of particulate matter and its specific chemical components from cooking: A review," Atmos. Environ., vol. 71, pp. 260-294, 2013,

[10] W. C. Wu and J. Y. Liou, "Numerical simulation of harmful gas distribution in a range hood with an improved flow channel," Microelectron. Reliab., vol. 99, no. May, pp. 245-261, 2019, 
[11] A. Marucci, M. Carlini, S. Castellucci, and A. Cappuccini, "Energy efficiency of a greenhouse for the conservation of forestry biodiversity," Math. Probl. Eng., vol. 2013, 2013,

[12] M. Carlini, S. Castellucci, A. Mennuni, S. Ferrelli, and M. A. Felicioni, "Application of a circular \& green economy model to a ceramic industrial district : An Italian case study," in AIP Conference Proceedings 2123, 2019, vol. 020087, no. July.

[13] M. Carlini and S. Castellucci, "Modelling the Vertical Heat Exchanger in Thermal Basin," in Computational Science and Its Applications - ICCSA 2011, 2011, pp. 277-286.

[14] S. Castellucci, M. Carlini, M. Guerrieri, and T. Honorati, "Stability and control for energy production parametric dependence," Math. Probl. Eng., vol. 2010, 2010,

[15] E. M. Mosconi, M. Carlini, S. Castellucci, E. Allegrini, L. Mizzelli, and M. Arezzo Di Trifiletti, "Economical assessment of large-scale photovoltaic plants: An Italian case study," Lect. Notes Comput. Sci. (including Subser. Lect. Notes Artif. Intell. Lect. Notes Bioinformatics), vol. 7972 LNCS, no. PART 2, pp. 160-175, 2013.

[16] M. Carlini, M. Villarini, S. Esposto, and M. Bernardi, "Performance analysis of greenhouses with integrated photovoltaic modules," Lect. Notes Comput. Sci. (including Subser. Lect. Notes Artif. Intell. Lect. Notes Bioinformatics), vol. 6017 LNCS, no. PART 2, pp. 206-214, 2010.

[17] M. Carlini, S. Castellucci, and M. Moneti, "Biogas Production from Poultry Manure and Cheese Whey Wastewater under Mesophilic Conditions in Batch Reactor," Energy Procedia, vol. 82, pp. 811-818, Dec. 2015, [Online]. Available: https://linkinghub.elsevier.com/retrieve/pii/S1876610215025771

[18] M. Carlini, S. Castellucci, and M. Moneti, "Anaerobic co-digestion of olive-mill solid waste with cattle manure and cattle slurry: Analysis of bio-methane potential," Energy Procedia, vol. 81, pp. 354-367, 2015,

[19] M. Moneti, A. Di Carlo, E. Bocci, P. U. Foscolo, M. Villarini, and M. Carlini, "Influence of the main gasifier parameters on a real system for hydrogen production from biomass," Int. J. Hydrogen Energy, vol. 41, 2016.

[20] M. Carlini, S. Castellucci, and A. Mennuni, "Water hyacinth biomass: Chemical and thermal pre-treatment for energetic utilization in anaerobic digestion process," Energy Procedia, vol. 148, pp. 431-438, 2018,

[21] M. Carlini, S. Castellucci, S. Cocchi, and A. Manzo, "Waste wood biomass arising from pruning of urban green in viterbo town: Energy characterization and potential uses," Lecture Notes in Computer Science (including subseries Lecture Notes in Artificial Intelligence and Lecture Notes in Bioinformatics), vol. 7972 LNCS, no. PART 2. pp. 242255, 2013.

[22] M. Carlini, S. Castellucci, A. Mennuni, and S. Selli, "Poultry Manure Biomass: Energetic Characterization and ADM1based Simulation," J. Phys. Conf. Ser., vol. 1172, no. 1, 2019.

[23] M. Carlini, S. Castellucci, E. Allegrini, and A. Tucci, "Down-hole heat exchangers: Modelling of a low-enthalpy geothermal system for district heating," Math. Probl. Eng., vol. 2012, 2012,

[24] M. Carlini and S. Castellucci, "Efficient Energy Supply from Ground Coupled Heat Transfer Source," in Computational Science and Its Applications -- ICCSA 2010, 2010, pp. 177-190.

[25] M. Carlini, S. Castellucci, A. Mennuni, and S. Selli, "Simulation of anaerobic digestion processes: Validation of a novel software tool ADM1-based with AQUASIM," Energy Reports, vol. 6, no. June, pp. 102-115, 2020,

[26] M. Carlini, S. Castellucci, and A. Mennuni, "Thermal and fluid dynamic analysis within a batch micro-reactor for biodiesel production fromwaste vegetable oil," Sustain., vol. 9, no. 12, 2017.

[27] S. Castellucci, A. Colantoni, M. Villarini, E. Mosconi, and M. Carlini, "An Economical Evaluation of Anaerobic Digestion Plants Fed with Organic Agro-Industrial Waste,” Energies, vol. 10, no. 8, p. 1165, 2017,

[28] M. Carlini, S. Castellucci, and S. Cocchi, "A Pilot-Scale Study of Waste Vegetable Oil Transesterification with Alkaline and Acidic Catalysts," Energy Procedia, vol. 45, pp. 198-206, 2014.

[29] D. Valentín, A. Guardo, E. Egusquiza, C. Valero, and P. Alavedra, "Use of Coandă nozzles for double glazed façades forced ventilation," Energy Build., vol. 62, pp. 605-614, 2013,

[30] H. D. Kim, G. Rajesh, T. Setoguchi, and S. Matsuo, "Optimization study of a Coanda ejector," J. Therm. Sci., vol. 15, no. 4, pp. 331-336, 2006,

[31] M. Jafari, H. Afshin, B. Farhanieh, and A. Sojoudi, "Numerical investigation of geometric parameter effects on the 
aerodynamic performance of a Bladeless fan," Alexandria Eng. J., vol. 55, no. 1, pp. 223-233, 2016,

[32] M. A. Anutha, A. Ravi, A. L. Dsouza, S. Kumar, and G. Tejaswini, "Development of Bladeless Thruster for an UAV Application," vol. 7, no. 5, pp. 856-864, 2020.

[33] M. A. Anutha, A. Ravi, A. L. Dsouza, S. Kumar, and G. Tejaswini, "Design, development and analysis of bladeless," no. 6, pp. 20-24, 2020.

[34] "BW Engineering, https://sites.google.com/view/bw-engineering/resources/ABAQUS-Library?authuser=0."

[35] C. S. Chung, S. L. Cornejo, M. Huo, and E. A. Finol, "A new concept in design of rheolytic thrombectomy devices: The Coanda effect," Proc. ASME Summer Bioeng. Conf. 2009, SBC2009, no. PART A, pp. 419-420, 2009,

[36] V. Castaneda and A. Valera-Medina, "Coanda flames for development of flat burners," Energy Procedia, vol. 158, pp. 1885-1890, 2019,

[37] J. E. Cater and J. Van Der Linden, "Medical Engineering \& Physics Simulation of carbon dioxide insufflation via a diffuser in an open surgical wound model," Med. Eng. Phys., vol. 37, no. 1, pp. 121-125, 2015,

[38] M. Carlini, A. Mennuni, E. Allegrini, and S. Castellucci, "Energy Efficiency in the Industrial Process of Hair Fiber Depigmentation: Analysis and FEM Simulation," in Energy Procedia, 2016, vol. 101.

[39] COMSOL Multiphysics, "CFD Module User 's Guide," COMSOL Multiphysics, p. 598, 2016.

[40] COMSOL, "Comsol multiphysics, Reference Manual".

[41] M. Carlini, S. Castellucci, A. Mennuni, and S. Morelli, "Numerical modeling and simulation of pitched and curved-roof solar greenhouses provided with internal heating systems for different ambient conditions," Energy Reports, 2019.

[42] M. Carlini, S. J. McCormack, S. Castellucci, A. Ortega, M. Rotondo, and A. Mennuni, "Modelling and Numerical Simulation for an Innovative Compound Solar Concentrator: Thermal Analysis by FEM Approach,” Energies, p. 27, 2020 ,

[43] M. Carlini, S. Castellucci, I. Ceccarelli, M. Rotondo, and A. Mennuni, "Study of a thermal dispersion in buildings and advantages of ceramic coatings for the reduction of energy expenditure," Energy Reports, vol. 6, no. June, pp. 116-128, 2020 ,

[44] M. Carlini, M. Rotondo, S. Selli, and A. Mennuni, "Simulation of a coil cooling system for an innovative compound solar concentrator plant by FEM approach," Energy Reports, vol. 6, no. June, pp. 129-142, 2020, 